\title{
Health, psychosocial, and economic impacts of the COVID-19 pandemic on people with chronic conditions in India: a mixed methods study
}

Kavita Singh ${ }^{1,2^{*}}$ D, Dimple Kondal ${ }^{1}$, Sailesh Mohan ${ }^{1,2,3}$, Suganthi Jaganathan ${ }^{2}$, Mohan Deepa ${ }^{4}$, Nikhil Srinivasapura Venkateshmurthy ${ }^{1,2}$, Prashant Jarhyan", Ranjit Mohan Anjana ${ }^{4}$, K. M. Venkat Narayan" Viswanathan Mohan ${ }^{4}$, Nikhil Tandon ${ }^{6}$, Mohammed K. Ali ${ }^{5}$, Dorairaj Prabhakaran ${ }^{1,2,7}$ and Karen Eggleston ${ }^{8}$

\begin{abstract}
Background: People with chronic conditions are disproportionately prone to be affected by the COVID-19 pandemic but there are limited data documenting this. We aimed to assess the health, psychosocial and economic impacts of the COVID-19 pandemic on people with chronic conditions in India.

Methods: Between July 29, to September 12, 2020, we telephonically surveyed adults $(n=2335)$ with chronic conditions across four sites in India. Data on participants' demographic, socio-economic status, comorbidities, access to health care, treatment satisfaction, self-care behaviors, employment, and income were collected using pre-tested questionnaires. We performed multivariable logistic regression analysis to examine the factors associated with difficulty in accessing medicines and worsening of diabetes or hypertension symptoms. Further, a diverse sample of 40 participants completed qualitative interviews that focused on eliciting patient's experiences during the COVID-19 lockdowns and data analyzed using thematic analysis.

Results: One thousand seven hundred thirty-four individuals completed the survey (response rate $=74 \%$ ). The mean (SD) age of respondents was 57.8 years (11.3) and 50\% were men. During the COVID-19 lockdowns in India, 83\% of participants reported difficulty in accessing healthcare, 17\% faced difficulties in accessing medicines, 59\% reported loss of income, 38\% lost jobs, and $28 \%$ reduced fruit and vegetable consumption. In the final-adjusted regression model, rural residence $(\mathrm{OR}, 95 \% \mathrm{Cl}: 4.01,2.90-5.53)$, having diabetes $(2.42,1.81-3.25)$ and hypertension $(1.70,1.27-2.27)$, and loss of income (2.30,1.62-3.26) were significantly associated with difficulty in accessing medicines. Further, difficulties in accessing medicines (3.67,2.52-5.35), and job loss (1.90,1.25-2.89) were associated with worsening of diabetes or hypertension symptoms. Qualitative data suggest most participants experienced psychosocial distress due to loss of job or income and had difficulties in accessing in-patient services.

(Continued on next page)
\end{abstract}

\footnotetext{
* Correspondence: kavita.singh@phfi.org

${ }^{1}$ Public Health Foundation of India, Plot number 47, Sector 44, Gurugram,

New Delhi, Haryana 122002, India

${ }^{2}$ Centre for Chronic Disease Control, New Delhi, India

Full list of author information is available at the end of the article
}

(c) The Author(s). 2021 Open Access This article is licensed under a Creative Commons Attribution 4.0 International License, which permits use, sharing, adaptation, distribution and reproduction in any medium or format, as long as you give appropriate credit to the original author(s) and the source, provide a link to the Creative Commons licence, and indicate if changes were made. The images or other third party material in this article are included in the article's Creative Commons licence, unless indicated otherwise in a credit line to the material. If material is not included in the article's Creative Commons licence and your intended use is not permitted by statutory regulation or exceeds the permitted use, you will need to obtain permission directly from the copyright holder. To view a copy of this licence, visit http://creativecommons.org/licenses/by/4.0/ The Creative Commons Public Domain Dedication waiver (http://creativecommons.org/publicdomain/zero/1.0/) applies to the data made available in this article, unless otherwise stated in a credit line to the data. 
(Continued from previous page)

Conclusion: People with chronic conditions, particularly among poor, rural, and marginalized populations, have experienced difficulties in accessing healthcare and been severely affected both socially and financially by the COVID-19 pandemic.

Keywords: SARS coronavirus, COVID-19 pandemic, Chronic conditions, India

\section{Background}

As the global burden of novel coronavirus disease 2019 (COVID-19) continues to increase, particularly in lowand middle- income countries such as India, it imposes huge costs on individuals, communities, health systems, and economies [1]. Although some countries and regions are seeing improvements in hospitalization and death rates, COVID-19 remains a major concern for vulnerable and underserved populations globally [2, 3]. People with chronic conditions are disproportionately prone to COVID-19-related hospitalizations, intensive care admissions, and mortality, compared to those without chronic conditions [4-7]. Moreover, they may be particularly susceptible to adverse health impacts from delayed or foregone care during the pandemic. The 2020 World Health Organization (WHO) report on the impact of COVID-19 on noncommunicable diseases (NCDs) in 163 countries highlighted that nearly half of the countries report that patients experienced partial or complete disruption of services for hypertension, diabetes, and related complications during the pandemic. One-third reported disrupted services for cardiovascular emergencies. Further, most countries reassigned the health staff towards COVID-19 support, which affected routine care for NCDs [8]. Several reports indicated change in routine care to virtual consultations and worsened mental health problems during the pandemic. Diabetes, chronic obstructive pulmonary disease, and hypertension were the most impacted conditions due to significant reduction in access to care [9-14]. Given the syndemic interaction -interrelationship between COVID-19 and various socio-ecological and biological factors contributing to preexisting NCD epidemicspeople with chronic conditions are more vulnerable to COVID-19 infection $[15,16]$.

As of March 11, 2021 more than 11 million people in India had been infected with COVID-19, and about 158, 000 had died [6]. The spread of COVID-19 in India is of great concern due to the country's large and densely populated areas with widespread poverty and high migration rates, coupled with a high prevalence of chronic conditions [17-19] that are generally poorly controlled [20-22]. Further, the progression of COVID-19 from urban to rural areas, the strict lockdown measures, and the associated economic shocks are likely to impede efforts to address other health scourges in India such as diabetes, hypertension, and cardiovascular diseases. On March 24, 2020, the Indian government ordered a nationwide lockdown, which was extended until June in four phases, and later further extended to specific containment zones. During the lockdowns, many health facilities were functioning sub-optimally or were converted to COVID facilities and provided only essential and emergency services.

Measures to address coronavirus spread including lockdowns may have serious economic consequences and unintended effect of exacerbating rather than mitigating health disparities $[8,9,23,24]$. However, to date, few data document the impact of the COVID-19 pandemic on disparities in chronic disease management in India. Given the unprecedented and rapidly evolving COVID-19 situation in India, we aimed to assess the health, psychosocial and economic impacts of COVID19 pandemic on people with chronic conditions in India.

\section{Methods}

\section{Study setting and participants}

We conducted a cross-sectional study using sequential mixed methods design, comprising a quantitative survey and qualitative interviews to describe the impact of COVID-19 on the health, psychosocial, and economic well-being of people with chronic conditions in India. Adults with one or more chronic conditions (hypertension, diabetes mellitus, cardiovascular disease, or chronic kidney disease), from the two large existing cohorts (the Centre for Cardio-metabolic Risk Reduction in South Asia, CARRS [25]; and a comprehensive diabetes and hypertension prevention and management program in India-UDAY [26]) were invited to participate in this study. The CARRS and UDAY study protocols and main study results have been published previously [14, 15]. Briefly, CARRS enrolled 12,271 adults aged $\geq 20$ years that were sampled to be representative of Delhi and Chennai in 2010-2011 and has followed them annually since. The UDAY study enrolled 12,243 adults in 201415 aged $\geq 30$ years from rural and urban communities in Sonipat (Haryana), and Visakhapatnam (Vizag), Andhra Pradesh, India. For this study, we used stratified random sampling of participants with chronic conditions by age and sex. We randomly selected and approached around 600 participants at each of the four sites (Delhi, Chennai Haryana and Vizag) in India. Furthermore, a diverse 
sample of 40 participants stratified by age, sex, comorbidities, and urban/rural sites were purposively selected for the qualitative interview. This study was approved by the Institutional Ethics Committees of the Centre for Chronic Disease Control, New Delhi, India, and the Madras Diabetes Research Foundation, Chennai, India. All participants provided verbal consent to this study over the phone.

\section{Data collection}

Between July 29 and September 12, 2020, we collected data on participants' demographic, socio-economic status, comorbidities, access to healthcare, difficulty in accessing medicines due to financial and non-financial (COVID-19 related) reasons, and treatment satisfaction. Quantitative survey questionnaire and qualitative study interview guide were developed by the authors for this mixed-methods study (Supplementary file 1). Participants were asked if their diabetes or hypertension symptoms worsened after lockdown. In addition, health status was assessed using EQ. 5D-VAS [27], and anxiety assessed using a generalized anxiety disorder (GAD) questionnaire [28]. Data on self-monitoring of blood glucose, adherence to diet plan, changes in physical activity, fruits and vegetables consumption pre- and post-lockdowns, employment status, and household income were collected using pre-tested questionnaire. Centralized online training was provided to the field workers to administer the survey over the telephone. Survey data were captured using Commcare application. Qualitative interviews were conducted in participant's local language by trained researchers (KS, SJ) and focused on eliciting patient's views on the challenges posed by the COVID-19 lockdowns and their mitigation.

\section{Statistical analysis}

We used a sequential mixed methods study design to guide our analytical approach $[29,30]$. Data are reported by study site and presented as a number (proportion) for categorical variables (e.g. access to health facility; diagnosed or hospitalized with COVID-19, loss of job or income) and a mean (SD) for normally distributed continuous variables (e.g., age, body mass index, health status score). GAD score [31] was defined as $0-4$ no anxiety, 5-9 mild anxiety, 10-14 moderate anxiety, 1521 severe anxiety. We performed bivariable and multivariable logistic regression analyses to find the factors associated with difficulty in accessing medicines and worsening diabetes or hypertension symptoms. We constructed three logistic regression models for each outcome. For the outcome "difficulty in accessing medicines", Model 1 included demographic variables (age, sex, education and income); Model 2 included demographic variables and chronic conditions (diabetes, hypertension, cardiovascular disease and chronic kidney disease); Model 3, in addition to model 2 variables, included financial support from government (yes/no), loss of job (yes/no), and loss of income (yes/no) during the COVID-19 lockdowns. Next, for the outcome "worsening diabetes or hypertension symptoms", Model 1 included demographic variables (age, sex, education and income); Model 2 included demographic variables and chronic conditions (diabetes, hypertension), GAD score (minimal, mild, moderate/severe), physical activity level, changes in fruit consumption during lockdown, and difficulty in accessing medicines (yes/no); Model 3, in addition to Model 2 variables, included financial support from the government (yes/no), loss of job (yes/no), and loss of income (yes/no) during the COVID-19 lockdowns. All data were analyzed using Stata version 16.0.

Qualitative data analyses focused on identifying views of individuals with chronic conditions, as well as the context, challenges, and mitigating factors or efforts to better manage chronic conditions during the COVID-19 pandemic in India. In-depth interviews with participants were audio-recorded, transcribed (verbatim), translated, anonymized, and checked for accuracy. The interview transcripts were coded thematically using MAXQDA software version 2020 [30]. Initial codes were developed and applied initially to a small number of transcripts, enabling further iteration of the thematic index [29, 32]. We used illustrative non-attributable quotations.

\section{Results}

\section{Participant characteristics}

Overall, 1734 out of 2335 contacted participants (74.3\% response rate) completed the survey. We found 58 cohort members $(2.5 \%)$ had died, 34 (1.5\%) refused to participate, and 509 (22\%) were not reachable for various reasons. Mean age (SD) of respondents was 57.8 (11.3) years, $50 \%$ were men, a majority had secondary school or college level education, and one-quarter of participants reported monthly household income of $>$ INR 30, 000 (Table 1). Most prevalent chronic conditions were hypertension (56\%), diabetes (43\%), and cardiovascular disease $(13 \%)$. Of the participants surveyed, $3 \%$ were diagnosed or treated for COVID-19, 1\% were hospitalized, and $69 \%$ reported that they had heard of a confirmed case of COVID-19 in their locality, more in urban (72\%) than rural $(58 \%)$ sites. About two-third of respondents experienced fear/anxiety related to COVID-19 and nearly half reported moderate difficulty in coping with stress during the COVID-19 lockdowns.

\section{Rural versus urban comparison}

Rural participants were disproportionately affected by the COVID-19 lockdowns compared with urban participants (Fig. 1). A greater proportion of rural participants 


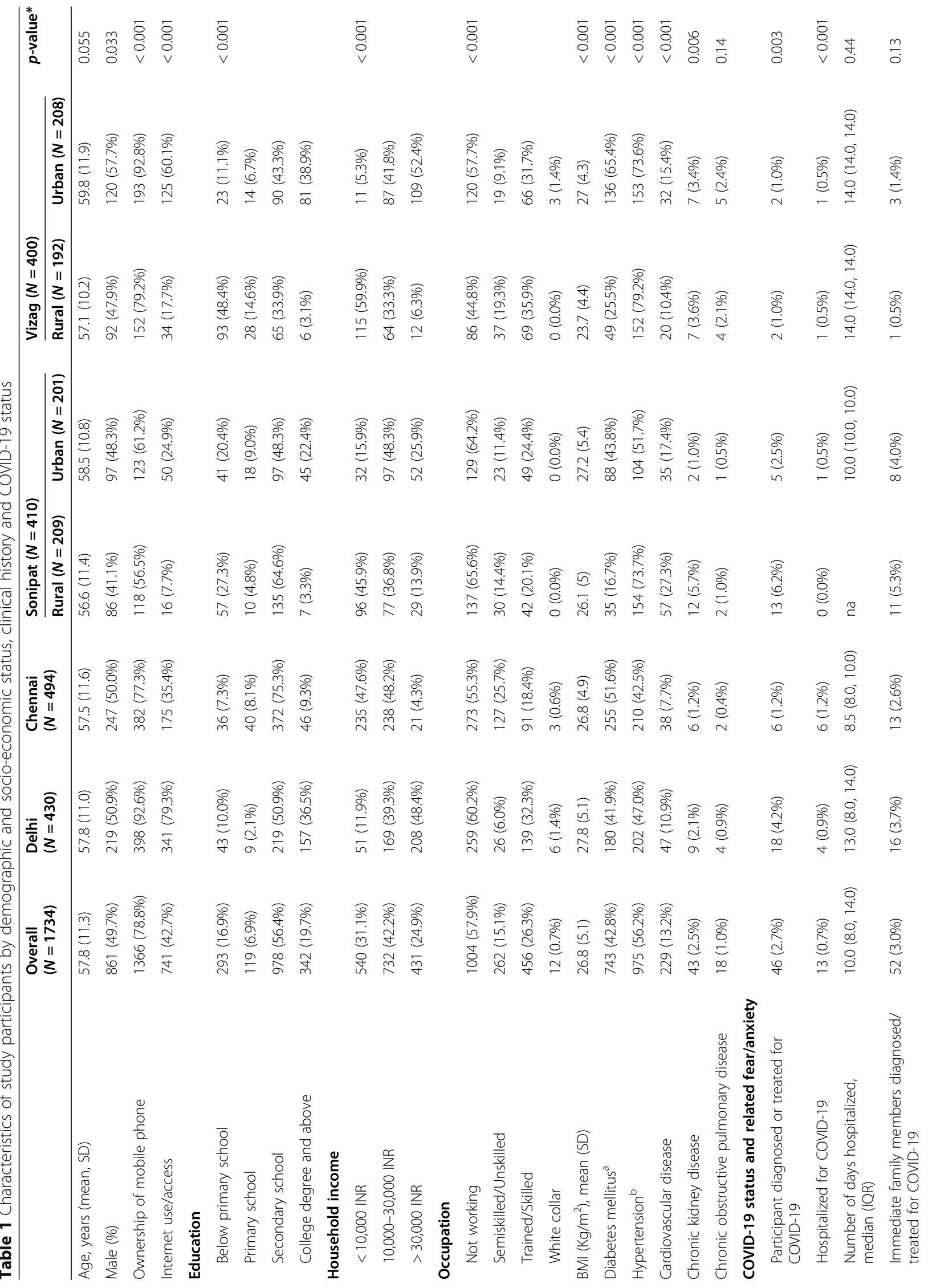









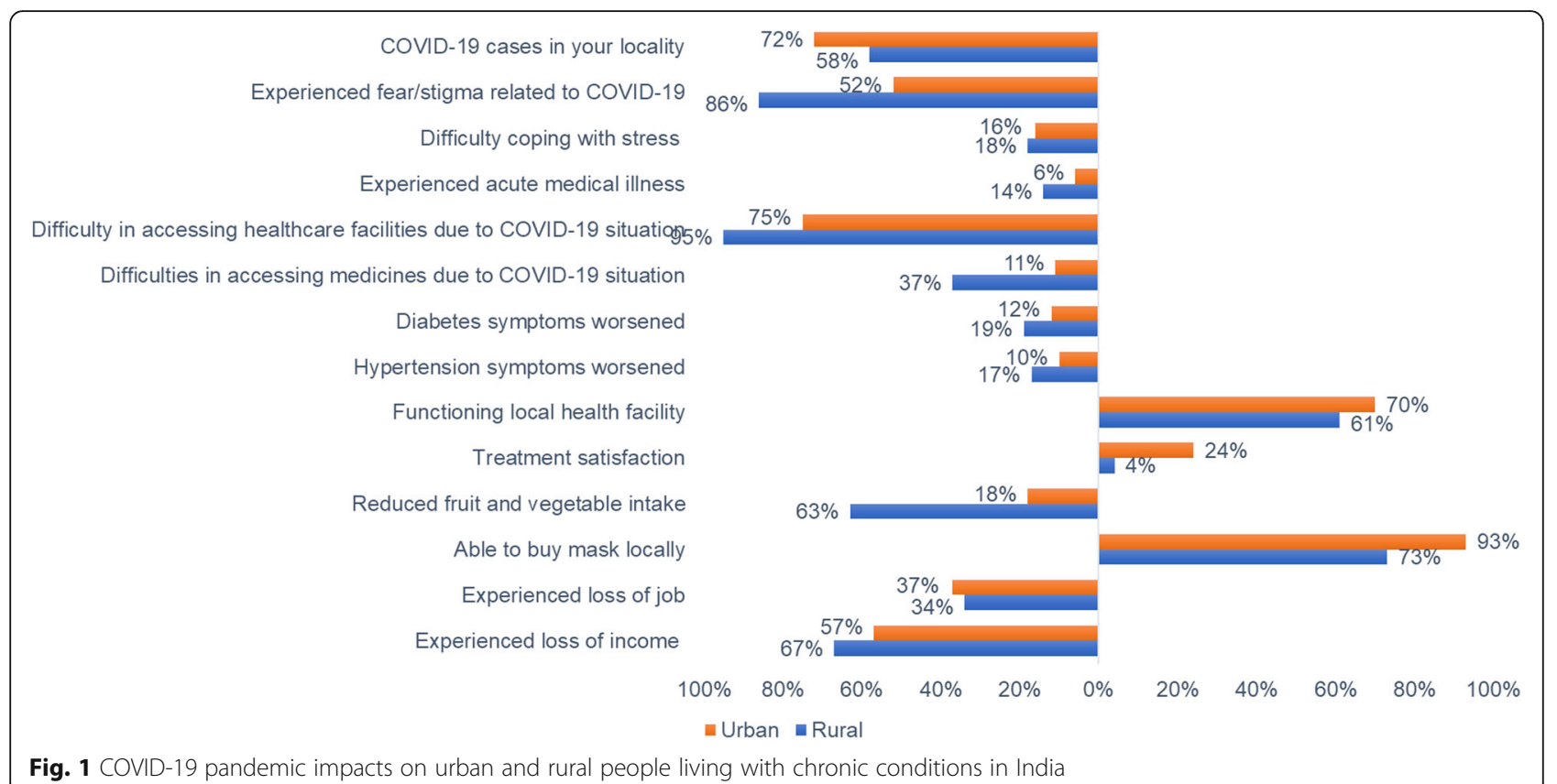

experienced acute medical illness (rural 14.2\%; urban 6.4\%), difficulties in accessing health facilities (rural 95.0\%; urban 75.0\%) and medicines (rural 36.9\%; urban $10.9 \%)$, worsened diabetes or hypertension symptoms (rural 16.0\%; urban 11.0\%), a lower treatment satisfaction rate (rural 3.5\%; urban 23.8\%), reduced fruit or vegetable consumption (rural $68.8 \%$, urban $28.7 \%$ ), and loss of household income (rural 67.3\%, urban 56.9\%).

\section{Health impacts}

Across the four sites, $8 \%$ of study participants experienced an acute medical illness during the COVID-19 related lockdowns (Table 2) with higher proportions being affected in rural sites (14\%). Two-thirds of patients reported that a local health clinic/hospital was functional during the COVID-19 lockdowns. Overall, the average health status score on EQ-VAS was 76.1; this was significantly lower in rural Vizag, 71.1. Nearly half the participants with diabetes or hypertension had their fasting blood sugar (FBS) or blood pressure (BP) tested during the lockdowns. Uncontrolled diabetes (FBS $>200 \mathrm{mg} / \mathrm{dl}$ ) was reported by $19.3 \%$ of participants and uncontrolled systolic BP (>140-160 mmHg) by $15.7 \%$. About onethird of respondents perceived their blood sugar to be controlled and $15 \%$ perceived their BP to be under control.

In the final-adjusted multivariable regression model, we found rural participants (odds ratio (OR), 95\% confidence interval (CI): 4.01,2.90-5.53), having diabetes (2.42,1.81-3.25) and hypertension (1.70,1.27-2.27), and loss of income $(2.30,1.62-3.26)$ were significantly associated with difficulty in accessing medicines. Financial aid from the government reduced the odds of difficulty in accessing medicines, i.e., had protective effect (OR: 0.69, 95\%CI:0.52-0.92) (Fig. 2 and online Table S1). Figure 3 and online Table S2 demonstrate the factors associated with worsening of diabetes or hypertension symptoms. In the regression Model 1, adjusted for demographic and socio-economic variables, we found rural participants and females had higher odds of worsening diabetes or hypertension symptoms compared with urban or male counterparts (OR, 95\%CI: 1.53,1.07-2.21 and 1.49,1.08-2.06, respectively). However, in the full multivariable-adjusted regression model, we found difficulties in accessing medicines $(3.67,2.52-5.35)$, loss of job $(1.90,1.25-2.89)$, and financial support from the government $(1.87,1.25-2.80)$ to be significantly associated with worsening of diabetes or hypertension symptoms.

\section{Psychosocial and economic impacts}

One-third of respondents did not adhere to their recommended diet plan and reduced fruit and vegetable consumption during the lockdowns (Table 3). About two-third of respondents did not perform physical activity and reported loss of household income, and onethird had lost jobs. Overall, $45 \%$ of participants had received financial support from the government, with large variation by site (93\% in Chennai vs. $8 \%$ in Delhi).

Because of the pandemic and related restrictions imposed to reduce its spread, few participants (15.2\%) reported visiting friends/family, although about half were able to leave their locality to buy food or other supplies $(52.6 \%)$. The majority reported that fruits, vegetables, 


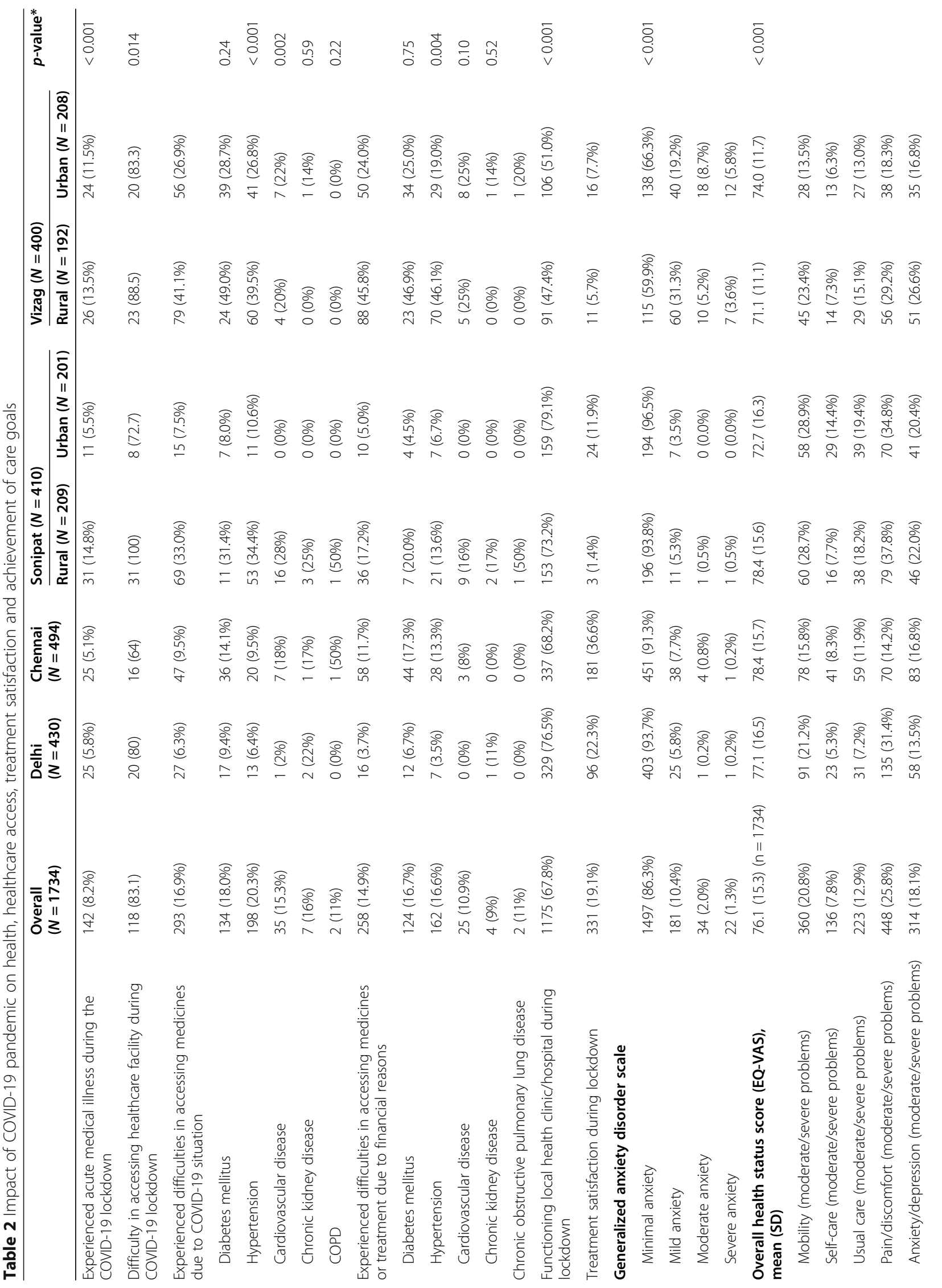




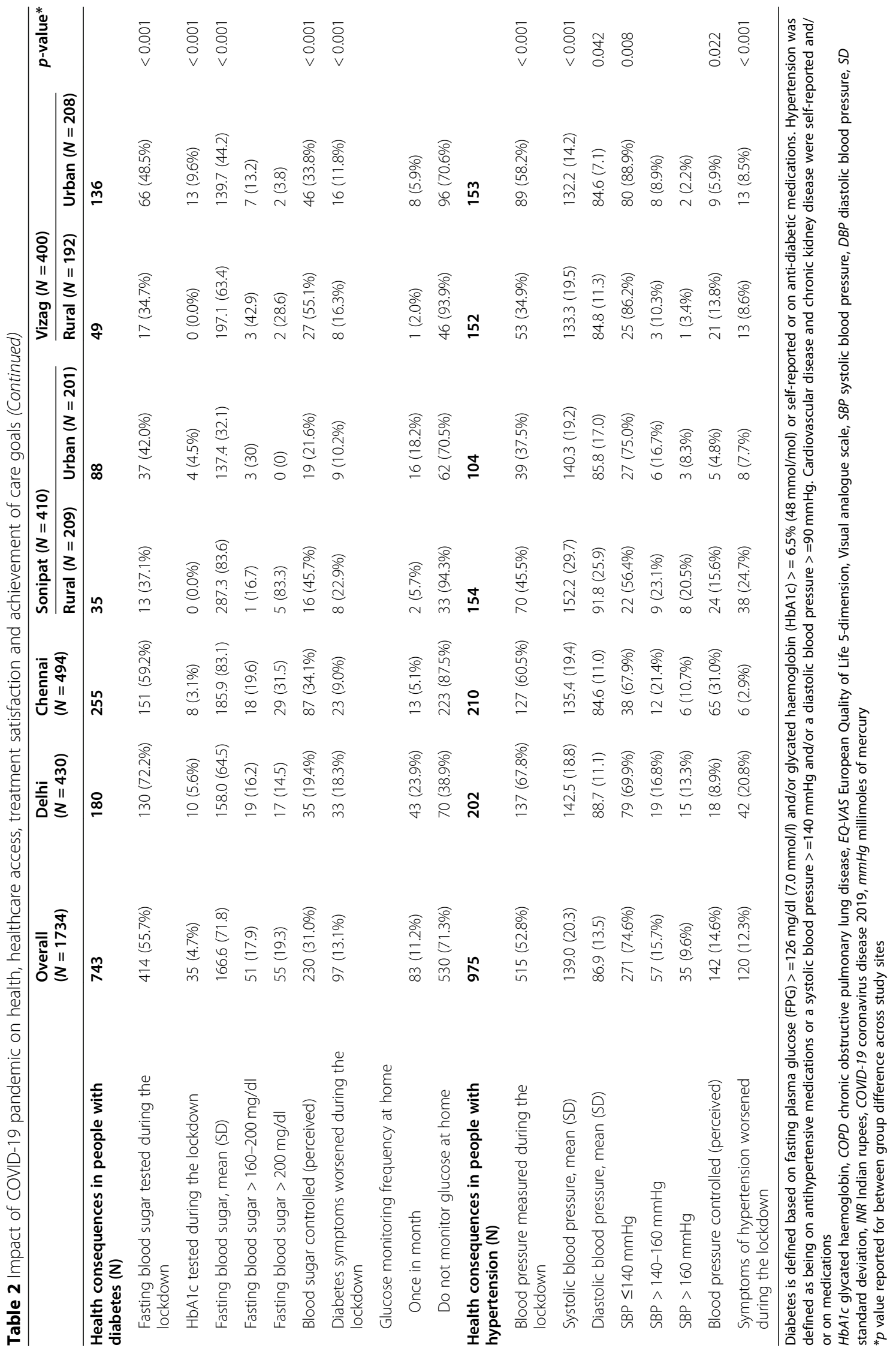




\begin{tabular}{|c|c|c|c|}
\hline & & Odds Ratio $(95 \% \mathrm{Cl})$ & $P$ value \\
\hline $\begin{array}{l}\text { Age } \\
<=45 \text { years } \\
46-60 \text { years } \\
>=60 \text { years }\end{array}$ & $\mapsto$ & $\begin{array}{c}1.00 \\
1.00(0.67,1.50) \\
1.04(0.69,1.58)\end{array}$ & $\begin{array}{l}0.988 \\
0.841\end{array}$ \\
\hline $\begin{array}{l}\text { Sex } \\
\text { Male } \\
\text { Female }\end{array}$ & & \\
\hline Site & $\Rightarrow$ & $\begin{array}{c}1.00 \\
4.01(2.90,5.53)\end{array}$ & $<0.001$ \\
\hline $\begin{array}{l}\text { Education } \\
\text { College degree and above } \\
\text { High school and secondary } \\
\text { Upto primary school }\end{array}$ & & $\begin{array}{c}1.00 \\
1.42(0.90,2.23) \\
1.61(0.95,2.74)\end{array}$ & $\begin{array}{l}0.130 \\
0.077\end{array}$ \\
\hline $\begin{array}{l}\text { Income (INR) } \\
>30,000 \\
10,001-30,000 \\
<=10,000\end{array}$ & & $\begin{array}{l}1.00 \\
0.74(0.50,1.09) \\
1.07(0.71,1.63)\end{array}$ & $\begin{array}{l}0.129 \\
0.734\end{array}$ \\
\hline $\begin{array}{l}\text { Disease conditions } \\
\text { Diabetes } \\
\text { Hypertension } \\
\text { CVD } \\
\text { Kidney }\end{array}$ & $\stackrel{\longmapsto}{\longmapsto}$ & $\begin{array}{l}2.42(1.81,3.25) \\
1.70(1.27,2.27) \\
1.11(0.77,1.60) \\
1.29(0.62,2.67)\end{array}$ & $\begin{array}{l}<0.001 \\
<0.001 \\
0.585 \\
0.498\end{array}$ \\
\hline \multirow{4}{*}{$\begin{array}{l}\text { Received financial support fr } \\
\text { Yes } \\
\text { Experienced loss of job } \\
\text { Yes } \\
\text { Experienced loss of income } \\
\text { Yes }\end{array}$} & $r+1$ & $0.69(0.52,0.92)$ & 0.012 \\
\hline & $t=1$ & $1.25(0.92,1.69)$ & 0.148 \\
\hline & $\longmapsto$ & $2.30(1.62,3.26)$ & $<0.001$ \\
\hline & 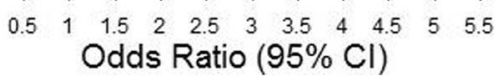 & & \\
\hline \multicolumn{4}{|c|}{$\begin{array}{l}\text { Fig. } 2 \text { Factors associated with difficulty in accessing medicines due to the COVID-19 situation. Diabetes is defined based on fasting plasma glucose } \\
(F P G)>=126 \mathrm{mg} / d \mathrm{dl}(7.0 \mathrm{mmol} / \mathrm{l}) \text { and/or glycated haemoglobin (HbAlc) }>=6.5 \%(48 \mathrm{mmol} / \mathrm{mol}) \text { or self-reported or on anti-diabetic medications. } \\
\text { Hypertension was defined as being on antihypertensive medications or a systolic blood pressure }>=140 \mathrm{mmHHg} \text { and/or a diastolic blood pressure }>=90 \\
\text { mmHg. Cardiovascular disease and chronic kidney disease were self-reported and/or on medications. INR=Indian rupees, } C V D=\text { cardiovascular disease, } \\
\text { Kidney = chronic kidney disease, } 95 \% \mathrm{Cl}=\text { confidence interval }\end{array}$} \\
\hline
\end{tabular}

and essential groceries were available during the lockdowns (96.8\%), although we do not know prices or quality. Most participants (99.4\%) reported being aware of and following recommended preventive measures such as wearing mask, handwashing, and social distancing (online Table S3).

\section{Qualitative study results}

Our sample consisted of 40 participants with one or more chronic conditions, mean age: 54.6 years, and $64 \%$ were men. Thematic redundancy was achieved with 8th interview, and two participants were then interviewed from each of the four sites (total, $N=40$ ) to confirm thematic redundancy. Interviews lasted about 20-40 min. Two major themes emerged from qualitative data analysis: "challenges faced", and "resilience and mitigating factors".

\section{Challenges faced}

Most participants faced financial difficulties during the COVID-19 lockdowns. Several participants reported difficulty getting to work because of lack of public transportation. Some participants lost their jobs due to the COVID-19 pandemic, as reflected in the following quotes from study participants:

"We faced difficulties at home because I am into driving. Before lockdown, I went home for some work. Because of lockdown, I had to stay at home for 2.5 months. I, my wife, and children are jobless since then. There was no possibility of doing any work or going anywhere. We had a lot of trouble at that time." $(R-02-V)$

"The impact was that there were a lot of problems. We took the ration distributed by the government. We consumed that. There were a few things [at home], we sold one or two things with the help of my daughter. My son drives a rickshaw, and my husband stays at home; we are old. It impacted him [spouse]. He was out of work for three months." (U-10-D)

Some participants had difficulty accessing inpatient services, since many hospitals were full or refused new 


\begin{tabular}{|c|c|c|c|}
\hline & & Odds Ratio ( $95 \% \mathrm{Cl})$ & $P$ value \\
\hline \multicolumn{4}{|l|}{ Age } \\
\hline$<=45$ years & & 1.00 & \\
\hline $\begin{array}{l}46-60 \text { years } \\
>=60 \text { years }\end{array}$ & & $\begin{array}{l}1.52(0.87,2.65) \\
0.91(0.50,1.65)\end{array}$ & 0.143 \\
\hline \multicolumn{4}{|l|}{ Sex } \\
\hline Male & & 1.00 & \\
\hline Female & & $1.24(0.86,1.79)$ & 0.253 \\
\hline \multicolumn{4}{|l|}{ Site } \\
\hline Urban & & 1.00 & \\
\hline Rural & & $1.53(0.95,2.45)$ & 0.081 \\
\hline \multicolumn{4}{|l|}{ Education } \\
\hline College degree and above & & 1.00 & \\
\hline High school and secondary & & $0.77(0.47,1.26)$ & 0.295 \\
\hline Upto primary school & $\mapsto-1$ & $0.76(0.41,1.43)$ & 0.395 \\
\hline \multicolumn{4}{|l|}{ Income (INR) } \\
\hline$>30,000$ & & 1.00 & \\
\hline $10,001-30,000$ & H+1 & $0.74(0.47,1.19)$ & 0.214 \\
\hline$<=10,000$ & & $1.18(0.69,2.01)$ & 0.555 \\
\hline \multicolumn{4}{|l|}{ Disease conditions } \\
\hline Diabetes & $\longmapsto$ & $2.48(1.70,3.62)$ & $<0.001$ \\
\hline Hypertension & & $2.30(1.55,3.41)$ & $<0.001$ \\
\hline \multicolumn{4}{|l|}{ General anxiety disorder } \\
\hline Minimal & & 1.00 & \\
\hline Mild & • & $0.90(0.53,1.52)$ & 0.695 \\
\hline Moderate/Severe & - & $1.36(0.67,2.76)$ & 0.395 \\
\hline \multicolumn{4}{|c|}{ Physical activity in the last one week } \\
\hline 0 days & & 1.00 & \\
\hline $1-3$ days & H & $0.90(0.53,1.52)$ & 0.711 \\
\hline \multicolumn{4}{|c|}{ Fruits consumption during lockdown } \\
\hline No change in fruit intake & & 1.00 & \\
\hline Increased fruit intake & & $1.49(0.78,2.85)$ & 0.222 \\
\hline Reduced fruit intake & $1-1$ & $0.83(0.56,1.24)$ & 0.367 \\
\hline \multicolumn{4}{|c|}{$\begin{array}{l}\text { Difficulty accessing medications due to COVID-19 situation } \\
\text { Yes }\end{array}$} \\
\hline \multicolumn{4}{|c|}{ Received financial support from government } \\
\hline Yes & $\longmapsto$ & $1.87(1.25,2.80)$ & 0.002 \\
\hline $\begin{array}{l}\text { Experienced loss of job } \\
\text { Yes }\end{array}$ & $\longmapsto$ & $1.90(1.25,2.89)$ & 0.002 \\
\hline \multicolumn{4}{|l|}{ Experienced loss of income } \\
\hline Yes & 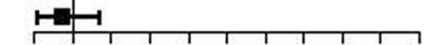 & $0.86(0.55,1.36)$ & 0.526 \\
\hline & 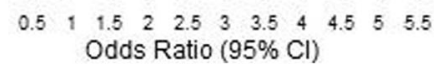 & & \\
\hline \multicolumn{4}{|c|}{$\begin{array}{l}\text { Fig. } 3 \text { Factors associated with worsening of diabetes or hypertension symptoms during the COVID-19 lockdown. Diabetes is defined based on } \\
\text { fasting plasma glucose }(F P G)>=126 \mathrm{mg} / \mathrm{dl}(7.0 \mathrm{mmol} / \mathrm{l}) \text { and/or glycated haemoglobin }(\mathrm{HbA} / \mathrm{C})>=6.5 \% \text { (48 mmol/mol) or self-reported or on anti- } \\
\text { diabetic medications. Hypertension was defined as being on antihypertensive medications or a systolic blood pressure }>=140 \mathrm{mmHg} \text { and/or a diastolic } \\
\text { blood pressure }>=90 \mathrm{mmHg} \text {. INR = Indian rupees, COVID-19= coronavirus disease } 2019,95 \% \mathrm{Cl}=\text { confidence interval }\end{array}$} \\
\hline
\end{tabular}

admissions due to COVID-19 cases. Many participants were concerned about visiting the hospital or doctor and delayed testing of their blood sugar because of fear and anxiety about COVID-19.

"I was not keeping well and none of the hospitals were taking any admission .. . they [hospital staff] said that due to COVID, beds are not available. And if you are ready to sleep on ground then we will take your admission." (U-08-V)

"I was scared that I may not have this [coronavirus infection] but because of someone else I may get affected. We have doubt to go to the hospital, to the doctor. I didn't want to get infected by this (COVID19)." (U-O2-D)

Participants with diabetes and hypertension were almost all aware of their elevated risk of poor outcomes if infected with SARS-CoV-2 and many feared to go out for a walk or other regular exercise.

\section{Resilience and mitigating factors}

Participants were well informed and emphasized the importance of wearing masks, practicing social distancing, or handwashing. Few participants utilized teleconsultations with doctors to avoid making in-person clinic visits. Most participants embraced the practice of 
Table 3 Social and economic consequences of COVID-19 pandemic

\begin{tabular}{|c|c|c|c|c|c|c|c|}
\hline \multirow[b]{2}{*}{ Impact on self-care behaviors } & \multirow{2}{*}{$\begin{array}{l}\text { Overall } \\
(N=1734)\end{array}$} & \multirow{2}{*}{$\begin{array}{l}\text { Delhi } \\
(N=430)\end{array}$} & \multirow{2}{*}{$\begin{array}{l}\text { Chennai } \\
(N=494)\end{array}$} & \multicolumn{2}{|c|}{ Sonipat $(N=410)$} & \multicolumn{2}{|c|}{ Vizag $(N=400)$} \\
\hline & & & & $\begin{array}{l}\text { Rural } \\
(N=209)\end{array}$ & $\begin{array}{l}\text { Urban } \\
(N=201)\end{array}$ & $\begin{array}{l}\text { Rural } \\
(N=192)\end{array}$ & $\begin{array}{l}\text { Urban } \\
(N=208)\end{array}$ \\
\hline \multicolumn{8}{|l|}{ Adherence to a meal plan in the last 1 week } \\
\hline 0 days & $553(36.2)$ & $179(51.6)$ & $227(54.7)$ & $48(25)$ & $46(25)$ & $37(20)$ & $16(7.8)$ \\
\hline $1-3$ days & $157(10.3)$ & $4(1.2)$ & $0(0)$ & $52(27.1)$ & $57(31)$ & $26(14.1)$ & $18(8.7)$ \\
\hline 4 or more days & 819 (53.6) & $164(47.3)$ & $188(45.3)$ & $92(47.9)$ & $81(44)$ & $122(66)$ & $172(83.5)$ \\
\hline \multicolumn{8}{|l|}{ Irregular eating pattern in the last 1 week } \\
\hline 0 days & $1365(78.7)$ & $388(90.2)$ & $456(92.3)$ & $126(60.3)$ & $116(57.7)$ & $134(69.8)$ & $145(69.7)$ \\
\hline $1-3$ days & $249(14.4)$ & $32(7.4)$ & $25(5.1)$ & $39(18.7)$ & $60(29.9)$ & $44(22.9)$ & $49(23.6)$ \\
\hline 4 or more days & $120(6.9)$ & $10(2.3)$ & $13(2.6)$ & $44(21.1)$ & $25(12.4)$ & $14(7.3)$ & $14(6.7)$ \\
\hline \multicolumn{8}{|l|}{ Physical activity in the last 1 week } \\
\hline 0 days & $1038(59.9)$ & $332(77.2)$ & $338(68.4)$ & $54(25.8)$ & $90(44.8)$ & $122(63.5)$ & $102(49)$ \\
\hline $1-3$ days & $202(11.7)$ & $36(8.4)$ & $12(2.4)$ & $83(39.7)$ & $54(26.9)$ & $7(3.7)$ & $10(4.8)$ \\
\hline 4 or more days & $494(28.5)$ & $62(14.4)$ & $144(29.2)$ & $72(34.5)$ & $57(28.4)$ & $63(32.8)$ & $96(46.2)$ \\
\hline \multicolumn{8}{|l|}{ Fruits consumption during lockdown vs. pre-lockdown } \\
\hline Reduced fruit intake & $658(37.9 \%)$ & $77(17.9 \%)$ & $153(31.0 \%)$ & $198(94.7 \%)$ & $94(46.8 \%)$ & $78(40.6 \%)$ & $58(27.9 \%)$ \\
\hline Increased fruit intake & $105(6.1 \%)$ & $40(9.3 \%)$ & $10(2.0 \%)$ & $1(0.5 \%)$ & $5(2.5 \%)$ & $13(6.8 \%)$ & $36(17.3 \%)$ \\
\hline No change in fruit intake & $971(56.0 \%)$ & $313(72.8 \%)$ & $331(67.0 \%)$ & $10(4.8 \%)$ & $102(50.7 \%)$ & $101(52.6 \%)$ & $114(54.8 \%)$ \\
\hline \multicolumn{8}{|c|}{ Vegetables consumption during lockdown vs. pre-lockdown } \\
\hline Reduced vegetable intake & $485(28.0 \%)$ & $49(11.4 \%)$ & $67(13.6 \%)$ & $191(91.4 \%)$ & $81(40.3 \%)$ & $61(31.8 \%)$ & $36(17.3 \%)$ \\
\hline Increased vegetable intake & $196(11.3 \%)$ & $46(10.7 \%)$ & $39(7.9 \%)$ & $2(1.0 \%)$ & $8(4.0 \%)$ & $35(18.2 \%)$ & $66(31.7 \%)$ \\
\hline No change in vegetable intake & $1053(60.7 \%)$ & $335(77.9 \%)$ & $388(78.5 \%)$ & $16(7.7 \%)$ & $112(55.7 \%)$ & $96(50.0 \%)$ & $106(51.0 \%)$ \\
\hline \multicolumn{8}{|c|}{ Duration and intensity of physical activity during lockdown vs. pre-lockdown } \\
\hline Decreased physical activity & $431(24.9 \%)$ & $42(9.8 \%)$ & $111(22.5 \%)$ & $149(71.3 \%)$ & $89(44.3 \%)$ & $10(5.2 \%)$ & $30(14.4 \%)$ \\
\hline Increased physical activity & $38(2.2 \%)$ & $10(2.3 \%)$ & $11(2.2 \%)$ & $2(1.0 \%)$ & $8(4.0 \%)$ & $0(0.0 \%)$ & $7(3.4 \%)$ \\
\hline No change in physical activity & $227(13.1 \%)$ & $46(10.7 \%)$ & $34(6.9 \%)$ & $4(1.9 \%)$ & $14(7.0 \%)$ & $60(31.3 \%)$ & $69(33.2 \%)$ \\
\hline \multicolumn{8}{|l|}{ Economic impact of COVID-19 } \\
\hline Experienced loss of job & $634(36.6 \%)$ & $163(37.9 \%)$ & $212(42.9 \%)$ & $86(41.1 \%)$ & $75(37.3 \%)$ & $49(25.5 \%)$ & $49(23.6 \%)$ \\
\hline Experienced loss of income & $1029(59.3 \%)$ & $203(47.2 \%)$ & $355(71.9 \%)$ & $131(62.7 \%)$ & $91(45.3 \%)$ & $139(72.4 \%)$ & $110(52.9 \%)$ \\
\hline Received financial support from the government & $774(44.6 \%)$ & $36(8.4 \%)$ & $460(93.1 \%)$ & $34(16.3 \%)$ & $14(7.0 \%)$ & $163(84.9 \%)$ & $67(32.2 \%)$ \\
\hline
\end{tabular}

COVID-19 coronavirus disease 2019

enhanced personal cleanliness and other measures to proactively reduce risks of COVID-19 infection and transmission.

"We have to be careful from the corona and we have to be safe from this. That's the only medicine now." (U-01-D)

\section{Discussion}

COVID-19 pandemic related restrictions implemented to control it had unforeseen adverse impacts on the health status, access to treatment, and achievement of care goals among people with chronic conditions in India. We found rural participants disproportionately experienced acute medical illnesses; difficulties in accessing healthcare; relatively less availability of functioning health facilities; poor treatment satisfaction; and reduced fruit and vegetable consumption.

Infectious disease epidemics have tended to have spillover effects onto the wider economy [14, 33-37]. This study showed that impacts of the pandemic extend beyond health to encompass adverse effects on household incomes, individual livelihoods, interpersonal relationships, coping skills, nutritional intake, and other factors. Our quantitative and qualitative data underscore significant economic impacts from loss of employment and household income in the study population, due at least in part to restrictions preventing workers from returning to work. Those repercussions may in turn lead to further stress and additional impacts on health. People with 
diabetes and hypertension were worst affected due to their difficulty in accessing health care and experienced worsening symptoms or uncontrolled BP or FBS during the lockdowns, which might lead to poor health outcomes and avoidable micro- and macrovascular complications. People with chronic conditions are known to be most vulnerable to the complications of COVID-19 as highlighted in the WHO global survey and several published reports $[8,9,23,38-40]$. It is unclear how the dual impact of COVID-19 and the health care disruptions affect these individuals in the long-term.

Our study results are consistent with other online surveys conducted among people with chronic conditions and healthcare providers that showed the coronavirus pandemic and its related lockdowns significantly reduced access to healthcare, adversely impacted self-care behaviors, and increased mental health problems [11, 15, $16,24,38]$. A recent study from India reported the effects of COVID-19-related lockdowns on the adoption of newer technologies and changes in glycemic control in patients with diabetes and found that the pandemic did not poorly affect glycemic control (HbAlc levels before vs. during lockdown: $8.2 \%$ vs. $7.7 \%$ ). However, that study was conducted at a single private clinic, and the higher socio-economic status of the surveyed participants could influence the study results [41]. Another cross-sectional study from India evaluating the impact of COVID-19 related lockdowns on changes in health behaviors and metabolic parameters in people with diabetes found that adherence to therapy, glycemic control, and monitoring did not differ significantly pre- and post-lockdowns [42]. However, in a sub-analysis of our study, we noted significant increase in the mean FBS reported during lockdown $(198 \mathrm{mg} / \mathrm{dl})$ vs. before lockdown $(165 \mathrm{mg} / \mathrm{dl})$ in the cohort participants. This indicates that people with diabetes appear to be at greater risk of experiencing uncontrolled blood sugar during the pandemic, which is consistent with the results of another study from India that found diabetes to be the most common comorbidity among COVID-19 decedents [43]. COVID-19 has also been a major concern in higherincome countries, with many European countries and the United States experiencing significant excess mortality in 2020 and a greater proportion of deaths from NCDs at home [44-49].

The COVID-19 pandemic is unprecedented and serious, and several of the policy measures taken to mitigate and contain it were necessary and understandable. At the same time, we believe that the data from our study provide insights for policy makers as they consider the asymmetrical psycho-social and economic impacts of the pandemic on people with chronic conditions, especially underprivileged urban residents and underserved rural communities. In our study, rural residents and those of lower educational attainment experienced more difficulties in accessing medicines, controlling for other demographics and self-reported income. Difficulty in access to medicines, in turn was associated with worsening of diabetes or hypertension symptoms. Global supply chain disruptions during the pandemic contributed to reported shortages of essential medicines for chronic conditions [50]. Furthermore, the pandemic caused people with chronic conditions to face many lifestyle disruptions (unhealthy diet and physical inactivity, sleep disturbances, stress, and anxiety) needing remedial measures $[16,51]$. Government aid was associated with fewer difficulties in access to medicines, but varied significantly across locations, demonstrating the importance of appropriate policies at the state and local levels. To mitigate the disparities in chronic disease management and reduce the potential longer-run health impacts of the current crisis, a promising approach is to focus on enabling access to medicines for vulnerable populations (i.e., those in rural areas, with lower educational attainment, and those experiencing poverty exacerbated by loss of jobs and household income). New models of healthcare delivery combined with new skills (e.g., patient-centered orientation and leveraging consumerfacing technologies) for the health workforce can promote patient engagement and health literacy, ultimately improving health outcomes.

Our data may assist health authorities to redesign care delivery models to address the urgent needs of people with chronic conditions. We recommend a threepronged approach to design resilient healthcare systems during and after the COVID-19 pandemic: a) develop and implement digital campaigns to disseminate information on how to adopt healthy behaviors, better selfmanage NCDs, and control COVID-19; b) decentralize healthcare delivery for people with chronic conditions by involving trained community health workers and using technology-assisted medical interventions along with home monitoring devices to improve health care services; c) provide effective social and economic support for people with chronic conditions, particularly rural communities, elderly, and those with severe mental health problems. Many have experienced loss of livelihoods, isolation, stress, and anxiety during the pandemic; however, those with preexisting chronic conditions have often experienced compounding effects that exacerbate their illness [52]. Therefore, social networks and family members have an important role to play within the community and at home in monitoring and enhancing self-care behaviors among patients with chronic conditions. Although regulatory authorities in many countries have approved one or more COVID-19 vaccines for emergency use, important challenges remain in mass producing and distributing vaccines in 
developing countries. In addition, the lasting and complex syndemic effects of the pandemic may linger; therefore, social health measures remain important. Greater investment in prevention efforts and strengthening primary care can help save future healthcare costs, reduce the burden of NCDs, and enhance resilience against future pandemics [53].

The strength of this study lies in its empirical mixed methods study design and focus on people with chronic conditions from both urban and rural populations. It is the first such study from a populous country like India. However, future research is needed to evaluate the longer-run impact of the COVID-19 pandemic on healthcare access and health outcomes for those both with and without NCDs.

\section{Limitations}

This study has important limitations. First, the crosssectional nature of this study limits the causal inferences between SES and chronic conditions and the COVID-19 pandemic related restrictions. Second, although the data are derived from a wide cross section of four sites, it cannot be construed as definitively representative of all urban and rural India. Third, because of the ongoing COVID-19 outbreak that we are studying, it was not possible to conduct the interviews in person; phone interviews may have limited the interpretation of qualitative data since they do not allow direct observation of participants' expressions and body language.

\section{Conclusion}

In response to the rapid spread of the COVID-19 pandemic and associated health system disruptions experienced in under-resourced and low-income settings, there needs to be renewed focus on building resilient health systems that can deliver routine care using innovative telehealth approaches during the pandemic and respond to the shocks induced by infectious disease pandemics or other health crises effectively. People living in rural areas and underserved communities in urban areas faced greater challenges in access to healthcare and experienced worsening of diabetes or hypertension symptoms, as well as significant losses of income and employment. The pandemic exposed disparities in chronic disease management, but also provides opportunities to close gaps with innovations in the new postCOVID India.

\section{Abbreviations}

BP: Blood pressure; CARRS: Centre for Cardiometabolic Risk Reduction in South Asia; CCDC: Centre for Chronic Disease Control; Cl: Confidence Interval; COVID-19: Coronavirus disease 2019; EQ 5D-VAS: European Quality of Life 5 Dimension - Visual Analogue Scale; FBS: Fasting Blood Sugar; GAD: Generalized Anxiety Disorder; MDRF: Madras Diabetes Research Foundation; NCD: Non-Communicable Disease; OR: Odds Ratio; SARS: Severe
Acute Respiratory Syndrome; SD: Standard Deviation; WHO: World Health Organization

\section{Supplementary Information}

The online version contains supplementary material available at https://doi. org/10.1186/s12889-021-10708-w.

Additional file 1: Table S1. Factors associated with difficulty in accessing medicines during the COVID-19 lockdowns in India. Table S2. Factors associated with worsening of diabetes or hypertension symptoms during the COVID-19 lockdowns in India. Table S3. COVID-19 pandemicrelated restrictions and preventive measures.

Additional file 2. Supplementary file.

\section{Acknowledgements}

Authors acknowledge the contributions of field teams for data collection, and study participants for their participation in this study.

\section{Authors' contributions}

$\mathrm{KE}, \mathrm{KS}, \mathrm{SM}$, and DP contributed to the conception and design of the study. SJ, DK, DM, SVN, PJ, ARM, KS, DP, EG, KMVN, and MKA had a role in acquisition, analysis, or interpretation of data. KS, DK, MKA, and KE drafted the manuscript, and all authors critically revised the manuscript. KE, DP, MKA, NT, VM, and KMVN provided technical and material support. All authors approved the final manuscript.

\section{Funding}

The CARRS Study was funded in part by the National Heart, Lung, and Blood Institute (NHLBI), National Institutes of Health $(\mathrm{NIH})$, Department of Health and Human Services, under Contract No. HHSN268200900026C, and the United Health Group, Minneapolis, MN, USA. UDAY is supported by an unrestricted educational grant from Eli Lilly and Company under the Lilly NCD Partnership Program. KS is supported by funding from the Fogarty International Centre, National Institutes of Health $(\mathrm{NIH})$, United States (grant award: 1K43TW011164). NSV is supported by the Fogarty International Centre and National Institute of Mental Health, of the National Institutes of Health under Award Number D43 TW010543. KMVN, and MKA, were funded in part by the National Institute of Diabetes and Digestive and Kidney Diseases of the National Institutes of Health under Award Number P30DK111024. DP was supported by Fogarty International Centre of the National Institutes of Health under Award Number U01TW010097. The funding agency had no role in the design, conduct, or analysis of the study, and no role in the decision to submit the manuscript for publication. The content is solely the responsibility of the authors and does not necessarily represent the official views of the National Institutes of Health. KE gratefully acknowledges funding from the Stanford Asia Health Policy Program, Asia-Pacific Research Centre faculty research award, and a seed grant from the Stanford Centre for Asian Health Research and Education.

\section{Availability of data and materials}

The datasets generated and analyzed during the current study are not publicly available because the datasets are currently used for another project but are available from the corresponding author on reasonable request.

\section{Declarations}

Ethics approval and consent to participate

Ethics approval for the study protocol was obtained from the Ethics Committee of Centre for Chronic Disease Control (CCDC), New Delhi and Madras Diabetes Research Foundation (MDRF), Chennai, Tamil Nadu, India. Verbal consent was obtained from all participants through telephone responses before the start of the survey. The Ethics Committee of CCDC and MDRF approved the procedure for obtaining informed consent.

Consent for publication

Not applicable.

Competing interests

The authors declare no conflict of interest. 


\section{Author details}

${ }^{1}$ Public Health Foundation of India, Plot number 47, Sector 44, Gurugram, New Delhi, Haryana 122002, India. ${ }^{2}$ Centre for Chronic Disease Control, New Delhi, India. ${ }^{3}$ Deakin University, Melbourne, Australia. ${ }^{4}$ Madras Diabetes Research Foundation, Chennai, India. ${ }^{5}$ Emory University, Atlanta, GA, USA. ${ }^{6}$ All India Institute of Medical Sciences, New Delhi, India. 'London School of Hygiene and Tropical Medicine, London, UK. ${ }^{8}$ Stanford University, Stanford, California, USA.

Received: 7 December 2020 Accepted: 24 March 2021 Published online: 08 April 2021

\section{References}

1. Coronavirus disease 2019 (COVID-19) Situation Report - 33.pdf. https://www. who.int/docs/default-source/coronaviruse/situation-reports/20200222sitrep-33-363 (Accessed 24 Sept 2020).

2. Garg S, Kim L, Whitaker M, O'Halloran A, Cummings C, Holstein R, et al. Hospitalization rates and characteristics of patients hospitalized with laboratory-confirmed coronavirus disease 2019 - COVID-NET, 14 states, March 1-30, 2020. MMWR Morb Mortal Wkly Rep. 2020;69(15):458-64. https://doi.org/10.15585/mmwr.mm6915e3.

3. Price-Haywood EG, Burton J, Fort D, Seoane L. Hospitalization and mortality among black patients and white patients with Covid-19. N Engl J Med. 2020:382(26):2534-43. https://doi.org/10.1056/NEJMsa2011686.

4. Thienemann F, Pinto F, Grobbee DE, Boehm M, Bazargani N, Ge J, et al. World heart federation briefing on prevention: coronavirus disease 2019 (COVID-19) in low-income countries. Glob Heart. 2020;15(1):31. https://doi. org/10.5334/gh.778.

5. Thienemann F, Ntusi NAB, Battegay E, Mueller BU, Cheetham M. Multimorbidity and cardiovascular disease: a perspective on low- and middle-income countries. Cardiovasc Diagn Ther. 2020;10(2):376-85. https:// doi.org/10.21037/cdt.2019.09.09.

6. https://www.worldometers.info/coronavirus/?utm_campaign=homeAdvega s1?. Accessed on 30 Sept 2020.

7. Hamer M, Kivimäki M, Gale CR, Batty GD. Lifestyle Risk Factors for Cardiovascular Disease in Relation to COVID-19 Hospitalization: A Community-Based Cohort Study of 387,109 Adults in UK. medRxiv [Preprint]. 2020;2020.05.09.20096438. https://doi.org/10.1101/2020.05.09.20096438. Update in: Brain Behav Immun. 2020. PMID: 32511498; PMCID: PMC7273266.

8. The impact of the COVID-19 pandemic on noncommunicable disease resources and services: results of a rapid assessment. Geneva: World Health Organization; 2020. https://www.who.int/publications/i/item/ncds-covid-ra pid-assessment. (Accessed on 10 Mar 2021).

9. Chudasama Y, Gillies CL, Zaccardi F, Coles B, Davies MJ, Seidu S, et al. Impact of COVID-19 on routine care for chronic diseases: a global survey of views from healthcare professionals. Diabetes Metab Syndr. 2020;14(5):9657. https://doi.org/10.1016/j.dsx.2020.06.042.

10. Su Z, McDonnell D, Wen J, Kozak M, Abbas J, Segalo S, et al. Mental health consequences of COVID-19 media coverage: the need for effective crisis communication practices. Glob Health. 2021;17(1):4. https://doi.org/10.1186/ s12992-020-00654-4.

11. Abbas J. The impact of coronavirus (SARS-CoV2) epidemic on individuals mental health: the protective measures of Pakistan in managing and sustaining transmissible disease. Psychiatr Danub. 2020:32(3-4):472-7. https://doi.org/10.24869/psyd.2020.472.

12. NeJhaddadgar N, Ziapour A, Zakkipour G, Abbas J, Abolfathi M, Shabani M. Effectiveness of telephone-based screening and triage during COVID-19 outbreak in the promoted primary healthcare system: a case study in Ardabil province, Iran. Z Gesundh Wiss. 2020:1-6. https://doi.org/10.1007/s1 0389-020-01407-8. Epub ahead of print. PMID: 33224715; PMCID: PMC7665795.

13. Addis SG, Nega AD, Miretu DG. Psychological impact of COVID-19 pandemic on chronic disease patients in Dessie town government and private hospitals, Northeast Ethiopia. Diabetes Metab Syndr. 2021;15(1):12935. https://doi.org/10.1016/j.dsx.2020.12.019.

14. Yoosefi Lebni J, Abbas J, Moradi F, Salahshoor MR, Chaboksavar F, Irandoost SF, et al. How the COVID-19 pandemic effected economic, social, political, and cultural factors: a lesson from Iran. Int J Soc Psychiatry. 2020: 20764020939984. https://doi.org/10.1177/0020764020939984. Epub ahead of print. PMID: 32615838.
15. Islam N, Lacey B, Shabnam S, Erzurumluoglu AM, Dambha-Miller H, Chowell $\mathrm{G}$, et al. Social inequality and the syndemic of chronic disease and COVID19: county-level analysis in the USA. J Epidemiol Community Health. 2021: jech-2020-215626. https://doi.org/10.1136/jech-2020-215626.

16. Yadav UN, Rayamajhee B, Mistry SK, Parsekar SS, Mishra SK. A syndemic perspective on the management of non-communicable diseases amid the COVID-19 pandemic in low- and middle-income countries. Front Public Health. 2020;8:508. https://doi.org/10.3389/fpubh.2020.00508.

17. India State-Level Disease Burden Initiative C. Nations within a nation: variations in epidemiological transition across the states of India, 19902016 in the global burden of disease study. Lancet. 2017;390(10111): 2437-60.

18. Anjana RM, Deepa M, Pradeepa R, Mahanta J, Narain K, Das HK, et al. Prevalence of diabetes and prediabetes in 15 states of India: results from the ICMR-INDIAB population-based cross-sectional study. Lancet Diabetes Endocrinol. 2017;5(8):585-96. https://doi.org/10.1016/S2213-8587(17)30174-2.

19. Prabhakaran D, Jeemon P, Ghosh S, Shivashankar R, Ajay VS, Kondal D, et al. Prevalence and incidence of hypertension: results from a representative cohort of over 16,000 adults in three cities of South Asia. Indian Heart J. 2017;69(4):434-41. https://doi.org/10.1016/j.ihj.2017.05.021.

20. Chatterjee P. Is India missing COVID-19 deaths? Lancet. 2020;396(10252):657. https://doi.org/10.1016/S0140-6736(20)31857-2.

21. The L. COVID-19 in India: the dangers of false optimism. Lancet. 2020; 396(10255):867

22. Debnath R, Bardhan R. India nudges to contain COVID-19 pandemic: a reactive public policy analysis using machine-learning based topic modelling. PLoS One. 2020;15(9):e0238972. https://doi.org/10.1371/journal. pone.0238972.

23. Danhieux K, Buffel V, Pairon A, Benkheil A, Remmen R, Wouters E, et al. The impact of COVID-19 on chronic care according to providers: a qualitative study among primary care practices in Belgium. BMC Fam Pract. 2020;21(1): 255. https://doi.org/10.1186/s12875-020-01326-3.

24. Saqib MAN, Siddiqui S, Qasim M, Jamil MA, Rafique I, Awan UA, et al. Effect of COVID-19 lockdown on patients with chronic diseases. Diabetes Metab Syndr. 2020;14(6):1621-3. https://doi.org/10.1016/j.dsx.2020.08.028.

25. Nair M, Ali MK, Ajay VS, Shivashankar R, Mohan V, Pradeepa R, et al. CARRS surveillance study: design and methods to assess burdens from multiple perspectives. BMC Public Health. 2012;12(1):701. https://doi.org/10.1186/14 71-2458-12-701.

26. Mohan S, Jarhyan P, Ghosh S, Venkateshmurthy NS, Gupta R, Rana R, et al. UDAY: a comprehensive diabetes and hypertension prevention and management program in India. BMJ Open. 2018;8(6):e015919. https://doi. org/10.1136/bmjopen-2017-015919.

27. Rabin R, de Charro F. EQ-5D: a measure of health status from the EuroQol group. Ann Med. 2001;33(5):337-43. https://doi.org/10.3109/078538901 09002087.

28. Toussaint A, Husing P, Gumz A, Wingenfeld K, Harter M, Schramm E, et al Sensitivity to change and minimal clinically important difference of the 7item generalized anxiety disorder questionnaire (GAD-7). J Affect Disord. 2020;265:395-401. https://doi.org/10.1016/j.jad.2020.01.032.

29. Fofana F, Bazeley P, Regnault A. Applying a mixed methods design to test saturation for qualitative data in health outcomes research. PLoS One. 2020; 15(6):e0234898. https://doi.org/10.1371/journal.pone.0234898.

30. Fisher MP, Hamer MK. Qualitative methods in health policy and systems research: a framework for study planning. Qual Health Res. 2020;30(12): 1899-912. https://doi.org/10.1177/1049732320921143.

31. Johnson SU, Ulvenes PG, Oktedalen T, Hoffart A. Psychometric properties of the general anxiety disorder 7-item (GAD-7) scale in a heterogeneous psychiatric sample. Front Psychol. 2019;10:1713. https://doi.org/10.3389/ fpsyg.2019.01713.

32. Johnson GA, Vindrola-Padros C. Rapid qualitative research methods during complex health emergencies: a systematic review of the literature. Soc Sci Med. 2017;189:63-75. https://doi.org/10.1016/j.socscimed.2017.07.029.

33. Fagoonee I, Pellicano R. COVID-19 brings the world economy to its knees. Minerva Med. 2020;111(4):297-9. https://doi.org/10.23736/S0026-4806.20.06603-3.

34. Bowie C, Hill T. Exit strategy to control covid-19 and relaunch the economy. BMJ. 2020;369:m1851.

35. Tiirinki H, Tynkkynen LK, Sovala M, Atkins S, Koivusalo M, Rautiainen $P$, et al. COVID-19 pandemic in Finland - preliminary analysis on health system response and economic consequences. Health Policy Technol. 2020;9(4): 649-62. https://doi.org/10.1016/j.hlpt.2020.08.005. 
36. Bonaccorsi G, Pierri F, Cinelli M, Flori A, Galeazzi A, Porcelli F, et al. Economic and social consequences of human mobility restrictions under COVID-19. Proc Natl Acad Sci U S A. 2020;117(27):15530-5. https://doi.org/10.1073/pna s.2007658117.

37. L'Angiocola PD, Monti M. COVID-19: the critical balance between appropriate governmental restrictions and expected economic, psychological and social consequences in Italy. Are we going in the right direction? Acta Biomed. 2020;91 (2):35-8. https://doi.org/10.23750/a bm.v91i2.9575.

38. Serlachius A, Badawy SM, Thabrew H. Psychosocial challenges and opportunities for youth with chronic health conditions during the COVID-19 pandemic. JMIR Pediatr Parent. 2020;3(2):e23057. https:/doi.org/10.2196/23057.

39. Camacho-Rivera M, Islam JY, Vidot DC. Associations between chronic health conditions and COVID-19 preventive behaviors among a nationally representative sample of U.S. adults: an analysis of the COVID impact survey. Health Equity. 2020;4(1):336-44. https://doi.org/10.1089/heq.2020.0031.

40. Extance A. Covid-19 and long term conditions: what if you have cancer, diabetes, or chronic kidney disease? BMJ. 2020;368:m1174.

41. Anjana RM, Pradeepa R, Deepa M, Jebarani S, Venkatesan U, Parvathi SJ, et al. Acceptability and utilization of newer technologies and effects on glycemic control in type 2 diabetes: lessons learned from lockdown. Diabetes Technol Ther. 2020;22(7):527-34. https://doi.org/10.1089/dia.2020.0240.

42. Kovil R, Shah T, Chawla M, Karkhanis S, Padhye D, Sanghvi A, et al. Patient reported changes in metabolic health during lockdown: a cross sectional digital connect survey in people with type 2 diabetes. Diabetes Metab Syndr. 2020;14(6):1907-12. https://doi.org/10.1016/j.dsx.2020.09.031.

43. Laxminarayan RWB, Dudala SR, Gopal K, Mohan C, Neelima S, Reddy K, et al. Epidemiology and transmission dynamics of COVID-19 in two Indian states. Science. 2020;370(6517):691-7. https://doi.org/10.1126/science.a bd7672.

44. Villani L, McKee M, Cascini F, Ricciardi W, Boccia S. Comparison of deaths rates for COVID-19 across Europe during the first wave of the COVID-19 pandemic. Front Public Health. 2020;8:620416. https://doi.org/10.3389/ fpubh.2020.620416.

45. Okell LC, Verity R, Watson OJ, Mishra S, Walker P, Whittaker C, et al. Have deaths from COVID-19 in Europe plateaued due to herd immunity? Lancet. 2020:395(10241):e110-1. https://doi.org/10.1016/S0140-6736(20)31357-X.

46. Khanijahani A, Tomassoni L. Socioeconomic and racial segregation and COVID-19: concentrated disadvantage and black concentration in association with COVID-19 deaths in the USA. J Racial Ethn Health Disparities. 2021. https://doi.org/10.1007/s40615-021-00965-1.

47. Gecili E, Ziady A, Szczesniak RD. Forecasting COVID-19 confirmed cases, deaths and recoveries: revisiting established time series modeling through novel applications for the USA and Italy. PLoS One. 2021;16(1):e0244173. https://doi.org/10.1371/journal.pone.0244173.

48. Scannell CA, Oronce CIA, Tsugawa Y. Association between county-level racial and ethnic characteristics and COVID-19 cases and deaths in the USA. J Gen Intern Med. 2020;35(10):3126-8. https://doi.org/10.1007/s11 606-020-06083-8.

49. Khazanchi R, Beiter ER, Gondi S, Beckman AL, Bilinski A, Ganguli I. Countylevel association of social vulnerability with COVID-19 cases and deaths in the USA. J Gen Intern Med. 2020;35(9):2784-7. https://doi.org/10.1007/s11 606-020-05882-3.

50. Badreldin HA, Atallah B. Global drug shortages due to COVID-19: impact on patient care and mitigation strategies. Res Social Adm Pharm. 2021;17(1): 1946-9. https://doi.org/10.1016/j.sapharm.2020.05.017.

51. Giuntella O, Hyde K, Saccardo S, Sadoff S. Lifestyle and mental health disruptions during COVID-19. Proc Natl Acad Sci U S A. 2021;118(9).

52. Abbas J. Crisis management, transnational healthcare challenges and opportunities: The intersection of COVID-19 pandemic and global mental health. In: Research in Globalization; 2021.

53. Wang ZDY, Jin Y, Zheng ZJ. Coronavirus disease 2019 (COVID-19) pandemic: how countries should build more resilient health systems for preparedness and response. Glob Health J. 2020;4(4):139-45. https://doi.org/10.1016/j. glohj.2020.12.001.

\section{Publisher's Note}

Springer Nature remains neutral with regard to jurisdictional claims in published maps and institutional affiliations.

\section{Ready to submit your research? Choose BMC and benefit from}

- fast, convenient online submission

- thorough peer review by experienced researchers in your field

- rapid publication on acceptance

- support for research data, including large and complex data types

- gold Open Access which fosters wider collaboration and increased citations

- maximum visibility for your research: over $100 \mathrm{M}$ website views per year

At $\mathrm{BMC}$, research is always in progress.

Learn more biomedcentral.com/submissions 